\title{
Interval and Speed of Convergence on Iterative Methods
}

\author{
Iswarmani Adhikari \\ Department of Mathematics, Prithvi Narayan Campus, Pokhara \\ Email: adhikariim35@gmail.com
}

\begin{abstract}
The iterative method is a tool of solving the non-linear equations to get their approximate roots with some errors of tolerance. Repetition of the similar process is applied successively on such iterations to compute a sequence of increasingly accurate estimates of the roots. In this paper, the construction of an iterative method for solving an equation, its convergence and the determination of interval of convergence for the approximate choice of initial guess and the speed of convergence are highlighted.
\end{abstract}

Keywords: Iteration, convergence, convergence interval, speed of convergence

\section{INTRODUCTION}

The rate at which a convergent sequence approaches its limit is the speed of convergence. The set of all values of $\mathrm{x}$ for which the sequence converges gives the interval of convergence. A power series often converge or diverge, depending upon the values of $\mathrm{x}$. If converges, the nature of convergence is also different.

Finding one or more roots of an equation $\mathrm{f}(\mathrm{x})=0$

--- (1) is one of the most commonly occurring problems of applied mathematics, specially on the numerical methods. For such equations, the explicit solutions are not available and their better approximations are obtained by different iterative methods. An iterative method is a powerful device of solving and finding the roots of the non-linear equations. Iteration means the act of repeating the similar process to achieve the desired goal where the result of one iteration is used as the starting point for the next operation. Successive approximations are used in each step to get more accurate solutions to a linear system and it involves a large number of iterations of arithmetic operations.

\section{CONVERGENCE OF $X_{\mathrm{N}}$}

Consider the equation be $\mathrm{f}(\mathrm{x})=\mathrm{a}-=0$

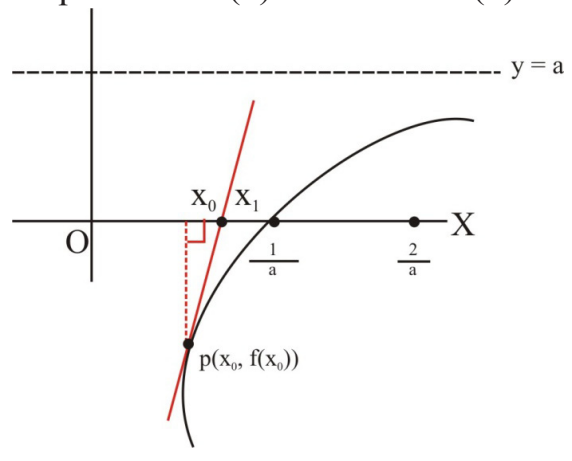

Let $\mathrm{x}_{0}$ be the initial guess. Let the tangent at $\mathrm{p}\left(\mathrm{x}_{0}, \mathrm{f}\left(\mathrm{x}_{0}\right)\right)$ meets the $\mathrm{x}$-axis as $\mathrm{x}_{1}$, then it becomes the better approximation of the root than $x_{0}$.

Slope of the tangent line $=$

$$
\backslash \mathrm{f}^{\prime}\left(\mathrm{x}_{0}\right)=
$$

Then, (2) becomes

$$
\begin{aligned}
& += \\
& \text { or, } \mathrm{x}_{0}-\mathrm{x}_{1}=\mathrm{ax}_{0}^{2}-\mathrm{x}_{0} \\
& \text { or, } \mathrm{x}_{1}=2 \mathrm{x}_{0}-\mathrm{ax}_{0}^{2} \text {. } \\
& \backslash \mathrm{x}_{1}=\mathrm{x}_{0}\left(2-\mathrm{ax}_{0}\right)-
\end{aligned}
$$

Equivalent to say, $x_{n+1}=x_{n}\left(2-a x_{n}\right)$--------- (5) for $\mathrm{n} \geq 0$, for the iterative methods.
Let $r_{n}=1-a x_{n}$
(6) then $x_{n+1}=x_{n}\left(1+r_{n}\right)$

where the error be

$$
\begin{aligned}
& e_{n}=-x_{n}== \\
& \backslash e_{n}=---
\end{aligned}
$$

From (6), we can write

$$
\begin{aligned}
r_{n+1} & =1-\operatorname{ax}_{n+1} \\
& =1-\operatorname{ax}_{n}\left(1+r_{n}\right), \text { from }(5) \\
& =1-\left(1-r_{n}\right)\left(1+r_{n}\right), \text { from }(6) \\
& =1-1+r_{n}^{2} \\
\backslash r_{n+1}= & r_{n}^{2}
\end{aligned}
$$

Here,

$\mathrm{n}=0 \mathrm{P} \mathrm{r}_{1}=\mathrm{r}_{0}^{2}$

$\mathrm{n}=1 \mathrm{P} \mathrm{r}_{2}=\mathrm{r}_{1}^{2}=\left(\mathrm{r}_{0}^{2}\right)^{2}=r_{0}^{2^{2}}$

$\mathrm{n}=2 \mathrm{P}_{3}=\mathrm{r}_{2}{ }^{2}=\left(\mathrm{r}_{0}^{4}\right)^{2}=r_{0}^{2^{3}}$, and so on.

$\backslash \mathrm{r}_{\mathrm{n}}=r_{0}{2^{n}}^{n}$--------- (9) for $\mathrm{n}^{3} 0$.

Thus from (9), we can say,

$\mathrm{r}_{\mathrm{n}}{ }^{\circledR} 0$ iff $\left|\mathrm{r}_{0}\right|<1$

iff $-1<\mathrm{r}_{0}<1$ 
iff $-1<1-\mathrm{ax}_{0}<1$, from (6)

iff $-2<-\mathrm{ax}_{0}<0$

iff $0<\mathrm{ax}_{0}<2$

iff $0<\mathrm{x}_{0}<$ (10) for $a>0$.

Hence, for the convergence of $x_{n}$ to, it is necessary and sufficient that $\mathrm{x}_{0}$ be chosen in between 0 and ; which tells us the interval of convergence on different iterative methods.

\section{Speed of Convergence}

The speed of convergence of a sequence can be determined as follows:

Let the sequence of real numbers be $\mathrm{x}_{0}, \mathrm{x}_{1}, \mathrm{x}_{2}, \ldots$ converges to $\alpha$. The speed of convergence is the rate at which the numbers are converging to $\alpha$.

If, $\lim _{n \rightarrow \infty}=\lambda<\infty$, then the sequence converges linearly to $\alpha$ where the constant $\lambda$ is called the asymptotic error.

$$
\text { If, } \lim _{n \rightarrow \infty} \frac{\left|x_{n+1}-\alpha\right|}{\left|x_{n}-\alpha\right|^{2}}=\lambda<\infty,
$$

then the sequence converges quadratically to $\alpha$.

Thus, if $\lim _{n \rightarrow \infty} \frac{\left|x_{n+1}-\alpha\right|}{\left|x_{n}-\alpha\right|^{p}}=\lambda<\infty$,

then the sequence converges to $\alpha$ of order $p$.

\section{Examples:}

i) Let $\mathrm{x}_{\mathrm{n}}=$ for some $\mathrm{k}>0$.

Clearly, it converges to 0 , where the rate of convergence be given by

$\lim _{n \rightarrow \infty} \frac{\left|x_{n+1}\right|}{\left|x_{n}\right|^{\alpha}}=\lim _{n \rightarrow \infty} \frac{\frac{1}{(n+1)^{k}}}{\frac{1}{n^{\alpha k}}}=\lim _{n \rightarrow \infty}\left(\frac{n^{\alpha}}{n+1}\right)^{k}$

We get the convergence for $\alpha=1$, but not for $\alpha=2$. Hence, the above sequence converges linearly to 0 . In fact, $\mathrm{x}_{\mathrm{n}}=, \mathrm{x}_{\mathrm{n}}=, \mathrm{x}_{\mathrm{n}}=, \ldots$ all converge linearly to zero.

ii) Let $x_{n}=0^{-2^{n}}$, which also converges to 0 . For the rate of convergence,

$$
\lim _{n \rightarrow \infty} \frac{\left|x_{n+1}\right|}{\left|x_{n}\right|^{\alpha}}=\lim _{n \rightarrow \infty} \frac{0^{-2^{n+1}}}{0^{-2^{n} \cdot \alpha}}
$$

$\backslash$ we get the convergence for $\alpha=2$.

Thus for the terms of the sequence be like $10^{-2}$, $10^{-4}, 10^{-8}, 10^{-16}, 10^{-32}, 10^{-64}, \ldots$ which shows the very fast convergence of order 2 , quadratically convergent.

\section{Relative error}

The magnitude of the difference between the exact value and the approximation is absolute error where the relative error is simply the ratio of absolute error to the exact value which can also be expressed in terms of percentage.

To examine the rate of decrease on the relative error, let us examine the speed of convergence from (6).

For this we write the above mentioned result be,,

$\mathrm{e}_{\mathrm{n}+1}===\mathrm{ae}_{\mathrm{n}}^{2}$

or, $=\mathrm{e}_{\mathrm{n}}^{2} \mathrm{a}^{2}=$

$\mathrm{P} \operatorname{Rel}\left(\mathrm{x}_{\mathrm{n}+1}\right)=\left[\operatorname{Rei}\left(\mathrm{x}_{\mathrm{n}}\right)\right]^{2}$, for $\mathrm{n}^{3} 0$, where $\operatorname{Rel}\left(\mathrm{x}_{\mathrm{n}}\right)$ denotes the relative error in $x_{n}$.

So, to know how fast the relative error will decrease, let Rel $\left(\mathrm{x}_{0}\right)=0.1$, where,

$\operatorname{Rel}\left(\mathrm{x}_{1}\right)=\left[\operatorname{Rel}\left(\mathrm{x}_{0}\right)\right]^{2}=0.01=10^{-2}$

$\operatorname{Rel}\left(\mathrm{x}_{2}\right)=\left[\operatorname{Rel}\left(\mathrm{x}_{1}\right)\right]^{2}=0.0001=10^{-4}$

$\operatorname{Rel}\left(\mathrm{x}_{3}\right)=\left[\operatorname{Rel}\left(\mathrm{x}_{2}\right)\right]^{2}=10^{-8}$

$\operatorname{Rel}\left(\mathrm{x}_{4}\right)=\left[\operatorname{Rel}\left(\mathrm{x}_{3}\right)\right]^{2}=10^{-16} \ldots$ and so on.

Here, the relative errors in each iterations double the number of significant digits, which provides the nature of the rate of its decrease in the relative errors.

\section{CONCLUSION}

An equation can be solved with the better approximations by the iterative approach with some reasonable errors. For the solution procedure, iterative method is a better tool for different non-linear equations to get their approximate solution where the repetition of the similar process is carried out successively to compute a sequence of increasingly accurate estimation of their solutions. In the convergence analysis of the solution of non-linear equations, the initial guess or the initial approximation within the interval of convergence and the speed of convergence play the vital role . 


\section{REFERENCES}

1. Atkinson, Kendall E. (2008). An Introduction to Numerical Analysis. John Wiley and Sons. Inc. U.K.

2. Brain Bradie (2007). A Friendly Introduction to Numerical Analysis. Prentice-Hall, Eaglewood Cliffs, N.J.

3. Faires, J. Dougles and Burden, Richard L. (2002). Numerical Methods. Brooks Cole, Canada.

4. Goldstine, H. (1977). A History of Numerical Analysis. Springer-verlang, New York.

5. Scheid, Francis (1968). Theory and Problems of Numerical Analysis. McGraw-Hill, New York.

6. Süli, Endre, and Mayers, David F. (2003). An Introduction to Numerical Analysis. Cambridge University Press, New York. 